\title{
IMPROVEMENT OF THE DIGITAL TRANSFORMATION STRATEGY OF BUSINESS ON THE BASIS OF DIGITAL TECHNOLOGIES
}

\author{
Pavlo Hrynko \\ Department of International Economics \\ Kharkiv State University of Food Technology and Trade \\ 333 Klochkivska str., Kharkiv, Ukraine, 61051 \\ pavelgrinko@gmail.com
}

\begin{abstract}
This paper is a theoretical and methodological substantiation of the provisions for the transformation of business in the digital economy and the development of practical recommendations for the formation of an organization's digital strategy. The characteristic features of changes in consumer behavior that contribute to improving the business management model in the digital economy through the development and implementation of a digital strategy are highlighted. The relevance of theoretical and methodological recommendations and organizational provisions of compositional management and the creation of a fundamentally new enterprise management subsystem are substantiated. Theoretical approaches to improving the organizational structure of enterprises in the digital economy are investigated. The goal and main trends in the field of human resources management are identified, which must be taken into account when forming the organization's digital strategy. The research models of the roadmap of digital transformation of the business, as well as the structural model of the digital development of the business model of the enterprise are presented.
\end{abstract}

Keywords: business management model, transformation, Digital technologies, Digital strategy.

DOI: $10.21303 / 2504-5571.2019 .001083$

\section{Introduction}

Currently, the challenges of globalization, the transition from an industrial to a digital economy, new speeds in business, mobility and transparency, the upcoming digital revolution, of course, need to be reviewed in the paradigm of doing business, its transformation from a traditional organization into a technological one. Without giving up the idea of maximum filtering of information, the development of information policy is carried out on the basis of new technologies that are able to integrate different systems and information sources. Innovative processes in the economy encourage the search for new solutions in enterprise management, which is explained by the introduction of modified tools focused on continuous and radical actions for progressive changes in the management system.

The process of interference in the development of an enterprise depends on internal and external factors, the chosen direction of its economic management policy. It is necessary to take into account changes in the structure and scope of business, the legislative framework, new market requirements, innovative processes, harmonization with the general development trend, etc. That is, a parallel solution of interconnected operational tasks for the implementation of strategic business goals should be carried out and organizing a high-quality information system required by various kinds of institutions or individual internal or external users.

This is due, first of all, to conditions such as a change in consumer behavior, which has the following characteristic features: an increase in the requirements for convenience and speed of acquisition of goods/services without leaving home; the possibility of access to assessing the quality of goods/services by other consumers (acquired after receiving feedback); payment by modern electronic means of payment becomes possible; receiving goods/services without visiting the store/ company (in the specified place - at home, in the office), etc.

All these requests are satisfied by the shift in the activity of organizations from the Internet to mobile applications, and the use of gadgets is becoming very common. Accordingly, with these circumstances, the enterprise management model takes on a different format, the radius and vector of which change under the influence of the main points of the effectiveness of the modern development of economic systems. That is, the issue of management effectiveness contributes to the study 
of the dialectic of information relations regarding the formation and dissemination of leadership when making alternatives to managerial decisions.

The issue of improving the business management model remains controversial in the scientific community, since scientists mainly deal with the problem of ensuring the long-term competitive success of enterprises, which depends on managerial decisions, projects and development scenarios. In addition, issues of improving mechanisms, tools, and means of managing entrepreneurial structures are considered [1]. The scientific community is studying issues related to the phenomenon of the "digital economy" [2,3], offers recommendations for deepening critical thinking and promoting the integration of sustainable development into the enterprise model with the expansion of the core competencies caused by the emergence of the digital economy in the national $[4,5]$, and in foreign literature $[6,7]$. The emergence of a new type of consumer and a change in the priorities of employees led to a change in the nature of labor and the relationship between the employer and the employee $[8,9]$, which determines the relevance of the development of the agility philosophy - flexibility and adaptability, the ability to quickly determine internal and external changes and respond to them in a timely manner, expanding opportunities and providing economic growth $[10,11]$. However, with the unconditional value of scientific research of the domestic and foreign community of scientists, the need remains to develop theoretical and methodological recommendations and organizational provisions for compositional management and create a fundamentally new enterprise management subsystem developed through the development and implementation of Digital strategies. It is necessary to determine the real mechanisms and tools for improving the enterprise model based on its personnel, assets and technologies, clarify the definition and highlight the main elements of the organization's Digital strategy, develop a practical algorithm for constructing the Organization's Digital strategy.

The aim of the article is the theoretical and methodological substantiation of the provisions on business transformation in the digital economy and the development of practical recommendations for the formation of an organization's digital strategy.

\section{Materials and methods}

The theoretical basis is based on observations, groupings, analytical work during the identification of problems and trends in the formation of the organization's Digital strategy, generalization of the results and development of recommendations for building a roadmap for digital business transformation, the organization's structural business model in the country. The theoretical basis of the study is the methodological and general scientific principles of conducting integrated research.

\section{Results}

\section{1. Development of a roadmap for digital business transformation}

In the modern economy, competition is increasingly becoming a competition not of resources, but of strategies, and investments by companies are increasingly directed towards creating key competencies and ensuring their dynamic abilities. Digital transformations, innovative potential, the ability to formulate more effective strategies and constantly develop a company, updating its structure and key business processes in response to environmental challenges, are playing an increasingly important role. The desire to win the competition puts forward new requirements for managers who should set ambitious but achievable goals, shape the vision of the future of the company and make it the property of all employees, stimulate the search and find new non-trivial solutions in transforming the enterprise's activities on a digital platform.

Business can choose any direction of development, guided by mission activities and available tools to influence processes. However, it is the digital transformation that is marked by the greatest potential, since it is a new prototype of the reconstruction of society and the economy, which is implemented by implementing a flexible modular complex of models and tools that are fully accessible for adaptation in traditional business models. The digital approach is a new business philosophy, it implies the presence and continuous development of feedback between business entities about the development of the economy, the engine of which is innovative technologies [12]. 
Paradoxically, digitalization does not consist in the total implementation of technologies, but in the profound transformation of business strategy. This is a complete update of the current business model, and therefore, a rethinking of the mission of the activity, processes, tools and tools. Digitalization is "saturation of the physical world with electronic digital devices, tools, systems and the establishment of electronic communication exchange between them. The goal of digitalization of Ukraine is the digital transformation of existing and the creation of new sectors of the economy, the transformation of all spheres of life of Ukraine into new, more efficient and modern" [13].

Digitalization is designed to update the way business structures function, change the approach to competitive relations, and adapt the business to market trends and factors. Digital transformation can't be a point in terms of change - it must be a full-fledged strategy that encompasses the entire organizational structure of the business. Achieving the goal of digital transformation is possible provided that a "roadmap" is developed, in which the main objectives, potential, opportunities, limitations and benefits of changes should be spelled out, which will allow for modernization at the right scale, pace, taking into account available resources (Fig. 1).

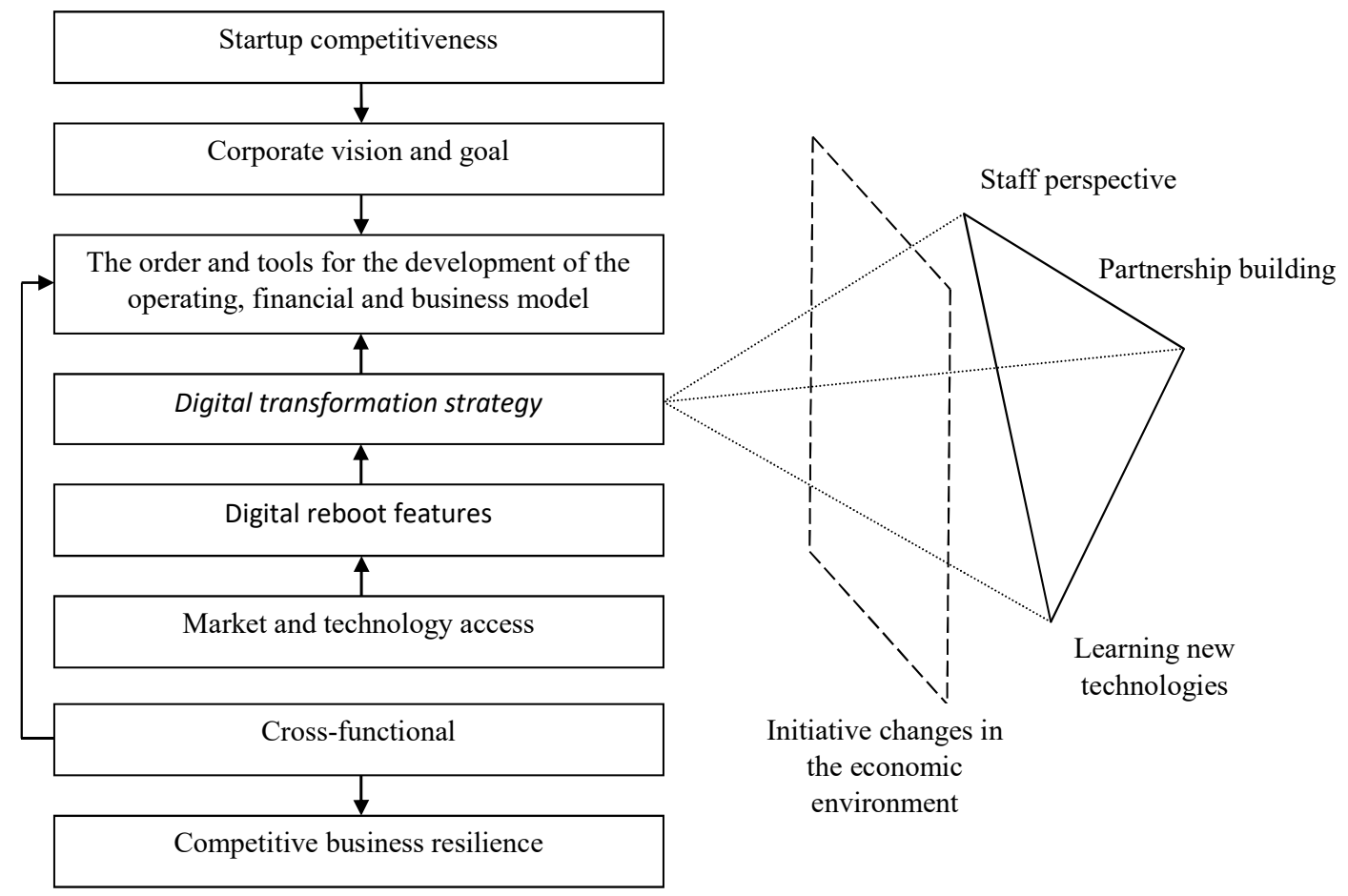

Fig. 1. Roadmap for digital business transformation

Thus, the digitalization strategy is based on three basic parameters: focus on personnel; partnership building; study of new technologies.

The staff is a key asset of the company, which can't be replaced by a virtual resource. The staff is endowed with professional competencies, which are the most important element of a transformational project for any scale and expected result. Digital transformation should be based on cross-functional teams, which are distinguished by an emphasis on achieving a common goal without individualizing functional responsibilities, and thanks to teamwork, self-regulation and the horizontal nature of leadership influence with the desire for the constant development of professional competencies and the acquisition of digital skills. Roles are necessarily distributed in such teams: initiator (prompting the development of a draft change and proposing innovations) coordinator (regulating the transformation and the relationship between team members) analytic controller (assessing the reality of the project and monitoring each stage of its development and implementation). Other specialists occupy the role of executors of specialists who are entrusted with the task of step-by-step execution of tasks. 
A cross-functional team should develop a digital startup, evaluate its strengths and weaknesses and conclude that there are sufficient resources for its implementation. When developing a new strategy, it is necessary to establish a culture of continuous study of technologies, which makes it possible to combine digital tools and solutions with the services of the enterprise, and therefore, allows to quickly adapt to the trends and requirements of the external economic environment.

The digital environment is a complete ecosystem with various levels of connectivity and partnership. Partnership promotion is one of the tools to generate business value, as it allows to borrow the best experience and form a developed business model. The company abandons the stereotypes of individualizing the business and continuously learns, focusing on the experience of market leaders, considering their organizational models from the perspective of digital business reloading opportunities, taking into account risks and limitations.

A distinctive feature of the digitalization roadmap is the rejection of a step-by-step evaluation of business sectors in favor of real changes without undue analysis. This approach is more effective, because the constant study of the aspects of the business allows to get a detailed picture of it, however, such information quickly becomes outdated, and therefore does not have a positive impact on changes. The roadmap allows to work out real mechanisms and tools of change with the proposal of an effective model, it is innovative in nature and is based on the key resources of the enterprise - staff, assets and technologies. In this case, the key competencies of the enterprise acquire a digital character and provide for the formation of a new personnel strategy and culture that corresponds to the technological basis of modernization.

\section{2. The main trends of digital strategy of the organization}

The field of Digital technologies in human resource management today is at the stage of origin, formation, formation, which does not allow an objective and in-depth analysis of their scientific definition. But, realizing the further expansion of the terminological apparatus according to the HR-Digital concept, it can be argued that it is based on an approach based on the principles of the integrity of the management model, dimension, data integration, real-time analysis and technological flexibility in the field of human resource management $[5,6,11]$. The goal of the HR-Digital concept, in our opinion, is to unite all areas of human resources management in combination with the capabilities of digital technologies for transparency, the sequence of building and measuring human capital management processes, similar to managing any other assets of an organization.

Studies of the opinions of scientists, economists, and experts at various levels made it possible to summarize the main trends in the field of human resource management, which must be taken into account when forming the organization's digital strategy, among which are the following (Fig. 2).

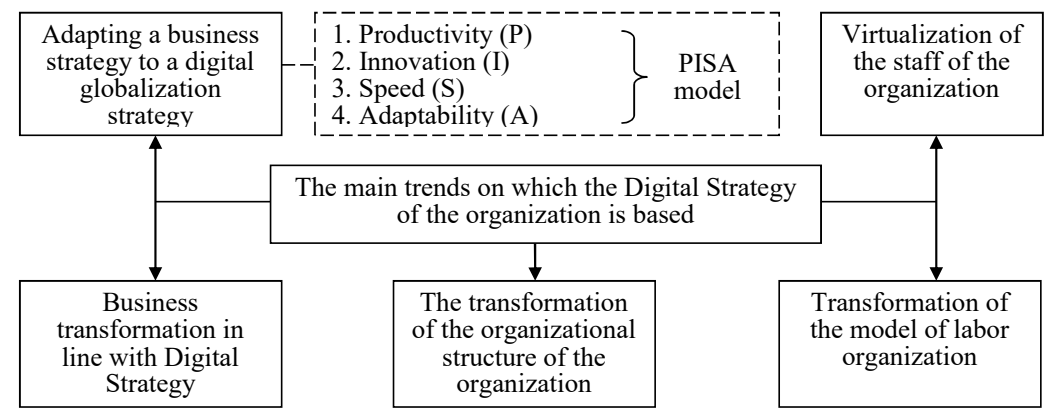

Fig. 2. The main trends in the formation of the digital strategy of the organization

1. Adapting a business strategy to the conditions of rapid changes in Digital globalization. J. Sullivan [14] connects the success of companies and their high market capitalization (Apple, Disney, Google, Amazon, Nike, etc.) with the PISA model, which includes ensuring performance in 4 directions: 
- Productivity - HR must measure and continuously increase labor productivity (i. e., income per employee);

- Innovation - HR should drive innovation, as it significantly increases economic value than productivity;

- Speed - the first who transforms, receives more profit and income, respectively, more stimulates its employees. To be fast, a company must learn fast;

- Adaptability - in an unstable world, constant transformation and adaptation, fast scale are essential.

2. Business requires equal rights and responsibility from HR departments for achieving financial and economic indicators, that is, HR is transformed into a real business partner and HR is integrated into the company's business processes.

3. The worldview of generation Y, which by 2020 will overtake generation $\mathrm{X}$ in the amount of $40 \%$ of the total workforce of developed countries, forms the concept of freedom - achieving the ideal balance between professional and personal life, which requires new models of work organization and human resource management.

4. Labor management will undergo fundamental transformations, changing, among other things, the stereotypes of traditional organizational structures: in parallel with the HR department, there is a personnel development unit (tasks for managing talents, knowledge and interests) and a Digital department headed by the corresponding director. The strengthening of the team of HR managers occurs through the involvement of economists, analysts and IT specialists to develop their professional competencies in the field of human resources management.

5. Active development and implementation of corporate mobile applications for working with staff in all areas - from recruiting to investment management.

\section{3. Development of a structural model of digital enterprise development}

Digitalization trends affect the business model of the enterprise with the possibility of forming a universal development strategy that meets the realities of the time and does not run counter to the physical basis of the economy, which is also an integral element of entrepreneurial relations (Fig. 3).

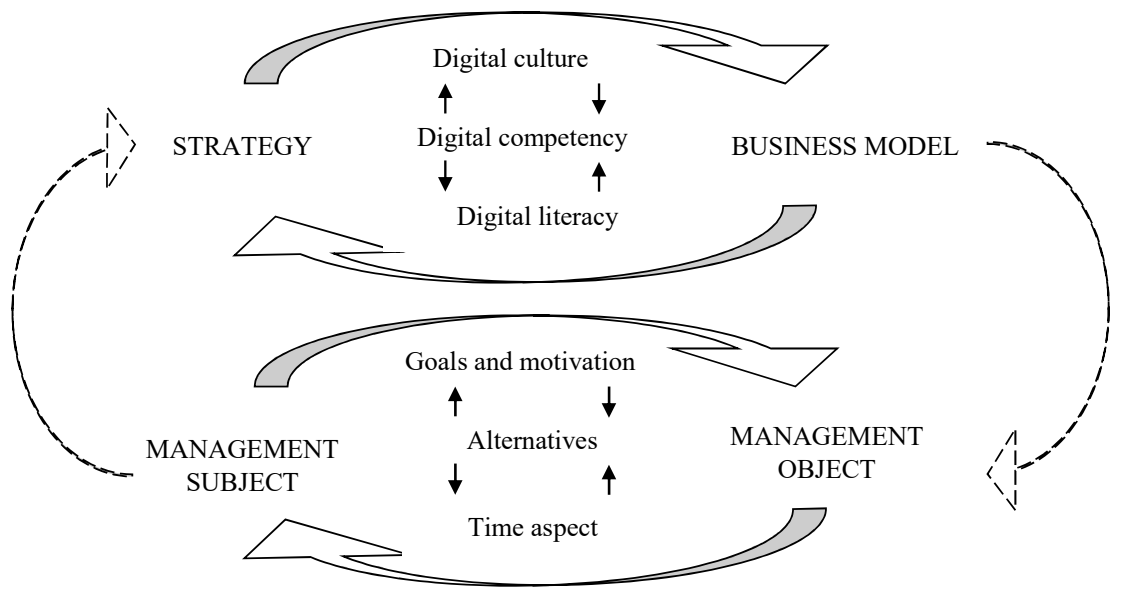

Fig. 3. The structural model of the digital development of the business model of the organization

In the model shown in Fig. 3, the implementation of the digital context by the traditional template of the organization's business model, in particular, the goals of developing new solutions, the temporary context of the activity, the basis for change and the subject of the leading influence are taken into account.

Each decision, a new goal affecting the business model, should be consistent with pre-selected decision templates as an alternative to the strategy. The business model should be adjusted 
as amended for the possible positive or negative impact of the new solution, thereby reducing the risk of an uncertainty situation.

The digital architectonics of changing the business model must be consistent with the time context of the enterprise and its readiness for transformation. According to the main feature, timeliness becomes, which is ensured by the necessary amount of information about the state and prospects of the business without minimizing possible risks. Digitalization should not occur spontaneously, but calculated with a clear understanding of the consequences of changes and a new development project. Otherwise, digital transformations will have the opposite effect - imitative development, which leads to the formation of a risky model of enterprise development.

Global technological trends and digitalization of the economy, in particular, contribute to the fact that the development and implementation of innovative technologies is becoming one of the key factors in increasing the competitiveness of organizations throughout the world and in Ukraine.

Therefore, the digital transformation strategy is a new prototype of reconstruction, namely a flexible modular set of tools and models that can be adapted to the needs of each organization in accordance with the expectations of continuous development and effective implementation of activities. Such a strategy is based on philosophy, which provides for feedback at the very beginning of work, when the product is still far from perfect, since this is what gives the best result.

That is, the chaotic nature of the world and the large-scale penetration of the Internet into all areas of life, including how to respond to changing consumer needs, stimulate business transformation - the transition from a traditional "product" technology company, the search for new management models that are based on the formation of a Digital Strategy.

According to the author, Digital strategy is not only a powerful disruptive force that allows to change the traditional organizational structure of the organization, but also the special cultural environment of continuous innovations and their constant adaptation to all new trends and market mechanisms in the digital economy, defines goals and directions enterprise IT movements. Using a digital strategy is an integral part of an organization's overall business strategy, develops key factors for its success and contributes to increasing the effectiveness of the management system, creating new competitive advantages and innovative business development.

Digital strategy is a formalized system of principles on the basis of which all components of the organization's information system are developed. The strategy provides an integrated approach to computerization of all enterprise management circuits and avoids the typical disadvantages of "private automation".

Let's consider the main components of the organization's Digital strategy in the digital economy and the mechanisms for its implementation:

1. Implementation of a personnel planning program. A human resources planning system should be introduced, fully harmonized with the digital transformation strategy. Firstly, it is necessary to conduct a survey and obtain data on the real correspondence of professional skills of the staff to the digital transformation program. After this, it is necessary to determine the list of posts that provide a digital transformation strategy. According to the selected group of digital innovators, it is necessary to determine the grid of professional competencies. The next stage is training either in-house (by using the experience of the staff in accordance with the assessment of information from the questionnaires), or through improving competencies in specialized courses. It is also important to introduce a model of best practice, constantly demonstrating the achievements of digital workers to motivate the entire team of employees. Incentive tools should be introduced, above all, of an intangible nature, and will become a stimulating factor for realizing professional potential.

2. Creating a collaborative environment. For its organization, it is necessary to allocate a separate room - it is enough to organize staff cooperation due to the use of digital technologies. It is necessary to take care of the association of workers not only in professional, but also in behavioral models. In advance, it is necessary to consider the mechanism for posting creative ideas with open access and the ability to evaluate and comment. Thus, collective interaction allows to bring to a new level the solution of tasks and ensure an effective communication climate. Employees should be interested in professional communication, which will become an alternative to social networks, which mostly spend free time. 
3. Demonstration of progress. This stage fits into the logic of the behavioral model of implementing digital transformations, since any system functions as a set of elements, and therefore, it is necessary to note the contribution of each employee to achieving the goal. On a project-wide scale, this allows to control each individual link and identify bottlenecks in advance that need improvement.

In digital - strategies should be defined: the philosophy of its development in the organization; place of IT departments in the enterprise structure; IT requirements in terms of business strategy; basic principles and directions of IT development; main directions for improving IT management processes; integrated characteristics of IT; budget and list of projects required to implement the IT strategy; quality assessments and performance targets of the IT system, as well as possible risks and alternative options for its development.

Digital strategy directly follows from the company's strategy (the principle of cascading from top to bottom) and answers the questions: how, from the IT point of view, the organization should work (business strategy: what to do in order to achieve its goals), corresponds to solving the problems facing the organization. As a rule, the main objectives of the Digital strategy are: reducing the operating costs of the enterprise and, in our opinion, the most important thing is to turn the IT service into a business engine.

The need to develop a Digital strategy is explained by: a significant dependence of the business on information technology (IT); desire to possess information, i.e. information leadership in the target market; a systematic approach to the implementation of the organization's joint strategic goals; user dissatisfaction with the current state of their information support; the emergence of new technologies that can increase the efficiency of the organization's core business; the IT budget is taking on dimensions that are noticeable by management; the status of the head of the IT service rises to the level of senior management.

\section{4. Practical Digital strategy development algorithm}

A well-built Digital strategy must meet the following requirements: scale, that is, the system must take into account the growing needs of the organization; flexibility, that is, the system should be easily tuned to changes in internal business processes and the external environment; be standardized, that is, the various components of the system must be compatible and meet the requirements of information security; economic efficiency, that is, the use of a solution must be economically justified; independence, that is, the customer should not become dependent on the decisions of suppliers, while there should be no need to maintain their own staff of programmers.

The development of the Digital strategy begins with the preparatory phase, which provides for the study, analysis and systematization of the main and auxiliary business processes of the company, as well as the analysis and improvement of information management principles of the organization.

After this, the stages of development of Digital strategy are formed:

1. An audit of existing information systems in the organization, the purpose of which is determination whether Digital strategy complies with the functional tasks of the business at different levels of management. That is, how much the organization's IS provides information to users, what is the structure of information flows, how the organization of data storage and access to them is carried out. Among the motives for changing or creating a new IS, organization managers may need to increase the reliability and accessibility of information, improve the quality of decisions made, ensure customer relationship management, manage the product life cycle or manage the supply chain to achieve operational excellence (for example, using supply sources on a global scale, the production of products and services for customers that match their individual preferences, etc.).

2. Modeling and analysis of the main and auxiliary processes. First of all, it is necessary to decide how the Digital strategy will influence the decision on the organization's business and support the decision-making process. Secondly, it is important to identify who will be the end users of IS. The appearance of one or another IS in an organization almost always entails a redistribution of key functions at the corporate governance level, since there is a transformation of business functions, business processes, and therefore the roles of personnel and departments. To carry out 
business functions and business processes, IS provides appropriate functional applications to end users and provides information exchange between them, creates the possibility of (collective) group work, work in projects, and the like. As a rule, this is supported on the basis of multichannel communications and platform integrity of the organization's portal. It serves as a single point of access to heterogeneous information, applications and services.

3. Setting goals and objectives for the development of information technology in accordance with the goals and objectives of the business. Technology can also be called the combination of a number of separate technologies for the transformation of information, each of which has its own dynamics of development. The volume of computerization, the type and nature of the use of hardware depends on the nature of a particular technology and the objectives of its implementation. The goal of any information technology is obtaining useful and high-quality information for the effective management of the organization. At the same time, there are restrictions on the cost of data processing, the complexity of the processes of using the information resource, the reliability and efficiency of the information processing process, and the quality of the information received. The information system can use many different information technologies for which this system acts as an implementation environment.

4. Development of a system project and a feasibility study of individual company informatization projects based on identified efficiency factors. The quality management system of projects implemented as part of the organization's project portfolio management should be interconnected with the general corporate management system. So, this consistency is manifested primarily in the fact that the organization is located at one of the levels of the external environment of the project, representing its immediate environment. Project quality management tools are divided according to management processes - planning, maintenance and quality control. The choice of tools depends on the specifics of the industry and the organization. The feasibility study tools for the project quality can be identified on the basis of efficiency factors:

- comparative analysis of costs and benefits: using this method, the potential benefits of quality requirements will be evaluated in the form of increased productivity, reduced errors, defects, non-compliance, reduced number of improvements with the cost of their implementation;

- cost of quality: this method allows to calculate the total cost of activities during the project aimed at improving quality. Costs due to defects are often divided into internal (identification within the project) and external (identification by the customer). So, the cost of compliance includes the cost of evaluation - various testing, inspection; cost of prevention - training, equipment, documentation of processes. In addition, the cost of the discrepancy is described in terms of internal costs, for example, the need for refinement and external - obligations, loss of profit and the like.

\section{Conclusions}

Thus, in modern conditions, a business develops under the influence of digital transformations and depends on the adaptation level to new conditions of economic relations, a whole line of business arises - a cluster of companies offering products and services in the field of digital technologies, including in the field of human resource management. The business is undergoing major changes, leading to the revision and improvement of its management models, which are the basis of competitiveness.

The digital business transformation strategy, which is based on Digital technologies, increases the efficiency of management decisions, automated recruiting, transition to virtual workplaces, individualization - creating an environment for each employee to fulfill and develop, manage HiPo and involvement, HR-analytics and performance management. However, which priorities are not used in approaches and technologies, it is the human potential of the company that is key - people who are able to generate and manage them. Intellectualization fundamentally changes the work of HR departments: from functional executives to strategic business partners.

The author identifies the main trends in the field of human resources management, which must be taken into account when forming the organization's digital strategy; a roadmap of digital business transformation has been developed, which presents real mechanisms and tools for improving the enterprise model based on its personnel, assets and technologies. 
A definition is given and the main elements of the Digital strategy of the organization are identified, and an algorithm for constructing the Digital strategy of the organization is developed, which is a priority area that can increase the effectiveness of its activities.

Thus, the digital initiative is the beginning of global changes, the "point of no return" for the business, and the transformation of the enterprise into a digital economic unit provides for the formation of new basic principles, operational procedures, technological updates, all of which will contribute to the business transformation.

\section{References}

[1] Shegda, A. V. (2002). Menedzhment. Kyiv: Znannya, KOO, 583.

[2] Keshelava, A. V., Budanov, V. G., Rumyantsev, V. Yu. et. al.; A. V. Keshelava (Ed.) (2017). Vvedenie v «Tsifrovuyu» ekonomiku». Moscow: VNIIGeosistem, 28.

[3] Dobrynin, A., Chernykh, K., Kupriyanovsky, V., Kupriyanovsky, P., Sinyagov, S. (2016). The digital economy - the various ways to the effective use of technology (BIM, PLM, CAD, IOT, SMART CITY, BIG DATA, and others). International Journal of Open Information Technologies, 4 (1), 4-11.

[4] Zhirov, V. F. (2011). Elektronniy menedzhment kak effektivnyy instrument globalizatsii. Nauka i sovremennost', 14, $275-280$.

[5] Golovina, V. V. (2013). Digital technologies in event - management. Sovremennye nauchnye issledovaniya i innovatsii, 6.

[6] Voytkevich, A. I., El-Smayli, D. P. (2016). The role of digital technology in the FMCG. Vestnik Rossiyskogo universiteta druzhby narodov. Seriya: Ekonomika, 4, 99-109.

[7] Bukht, R., Heeks, R. (2018). Defining, Conceptualising and Measuring the Digital Economy. International Organisations Research Journal, 13 (2), 143-172. doi: https://doi.org/10.17323/1996-7845-2018-02-07

[8] Mesenbourg, T. L. (2001). Measuring of the Digital Economy. The Netcentric Economy Symposium. University of Maryland.

[9] Tapscott, D. (1996). The Digital Economy: Promise and Peril in the Age of Networked Intelligence. New York, NY: McGraw-Hill, 342.

[10] Pavlyukovskaya. V. (2016). Kto i kak budet formirovat' kompetentsii liderov dlya novoy konkurentsii. Doklad na Pervoy Mezhdunarodnoy konferentsii «Bol'she chem obuchenie: gotovim liderov tsifrovogo mira».

[11] Meyer, P. (2015). Agility Shift: Creating Agile and Effective Leaders, Teams, and Organizations. Routledge, 240. doi: https:// doi.org/10.4324/9781315230559

[12] Rogers, R. (2013). Digital methods. MIT Press. doi: https://doi.org/10.7551/mitpress/8718.001.0001

[13] Sokolova, H. (2018). Some aspects of the development of the digital economy in Ukraine. Ekonomichnyi visnyk Donbasu, 1 , 92-96.

[14] Sullivan, J. (2016). Doklad na Mezhdunarodnom sammite HR - Digital. Moscow.

Received date 29.10.2019

Accepted date 21.11.2019

Published date 30.11.2019
(C) The Author(s) 2019

This is an open access article under the CC BY license (http://creativecommons.org/licenses/by/4.0). 